\title{
Role of Amorphous Phases in Enhancing Performances of Electrode Materials for Alkali Ion Batteries
}

\author{
Fangyu Xiong ${ }^{1}$, Haizheng Tao $^{1 *}$ and Yuanzheng Yue ${ }^{1,2 *}$ \\ ${ }^{1}$ State Key Laboratory of Silicate Materials for Architectures, Wuhan University of Technology, Wuhan, China, ${ }^{2}$ Department of \\ Chemistry and Bioscience, Aalborg University, Aalborg, Denmark
}

\section{OPEN ACCESS}

Edited by:

Takayuki Komatsu,

Nagaoka University of Technology,

Japan

Reviewed by:

Ana C. M. Rodrigues, Federal University of São Carlos, Brazi

Tsuyoshi Honma,

Nagaoka University of Technology,

Japan

Fuxiang Zhang,

Oak Ridge National Laboratory (DOE),

United States

*Correspondence:

Haizheng Tao

thz@whut.edu.cn

Yuanzheng Yue

yy@bio.aau.dk

Specialty section: This article was submitted to

Glass Science,

a section of the journal

Frontiers in Materials

Received: 15 August 2019 Accepted: 02 December 2019 Published: 08 January 2020

Citation:

Xiong F, Tao H and Yue Y (2020) Role of Amorphous Phases in Enhancing

Performances of Electrode Materials

for Alkali Ion Batteries.

Front. Mater. 6:328.

doi: 10.3389/fmats.2019.00328
As one of the most competitive energy storage systems owing to their high energy density, conversion efficiency, long lifetime, and environment friendliness, alkali ion batteries have been widely used and continue to exhibit their potential to be the crucial components of future energy technologies. To further improve electrochemical performances of alkali ion batteries, great efforts have been put into the development of advanced electrode materials. However, scientists are facing great challenges in developing superior electrode materials due to the limitation of the existing technologies. Therefore, we recently chose a different route, that is, the amorphization engineering, to develop high-performance electrodes. Here, we review some recent studies about the role of amorphous phases in promoting electrochemical performances of both cathodes and anodes for alkali ion batteries. In addition, we review some progress in revealing the microscopic mechanisms of the increased ionic/electronic transport as well as the enhanced structural stability in electrodes, achieved by amorphization engineering.

Keywords: electrode materials, amorphization engineering, electrochemical performance, lithium ion batteries, sodium ion batteries, glass

\section{INTRODUCTION}

Energy storage technology is located at an important position in modern society because of its necessity in many fields, such as smart grids, electric vehicles, and electronics (Lee et al., 2014; Larcher and Tarascon, 2015; Liu et al., 2015). Among various energy storage systems, lithium ion batteries (LIBs) have been widely applied owing to their high-energy density, conversion efficiency, and long lifetime (Goodenough and Park, 2013; Manthiram et al., 2014; Lee et al., 2018; Zhan et al., 2018). Besides, sodium ion batteries (SIBs), another family of alkali ion batteries (AIBs), also drew much research interest in the past decade because of the similar properties to those of LIBs, the high abundance and low cost of sodium reserves (Pan et al., 2013; Yabuuchi et al., 2014; Xiang et al., 2015). However, with the fast development of science and technology, the electrochemical performances of these AIBs are encountering a bottleneck to be further improved for the growing requirement of many new application fields. Therefore, further improving the electrochemical performances of AIBs is the continuous pursuit of scientists and engineers.

To further enhance the electrochemical performances of AIBs, great efforts have been focused on the fabrication of new nanostructures in electrode materials through the atomic-scale design strategy during the past decades (Kang and Ceder, 2009; Sun Y. K. et al., 2012; Zhang et al., 2014; Xiong et al., 2015; Qing et al., 2016; Deng et al., 2017; Wei et al., 2017). However, another important 
strategy, i.e., amorphization engineering, recently received much attention considering the unique functionalities of amorphous phases (Liu et al., 2012; An et al., 2014; Fang et al., 2014; Mathew et al., 2014; Kim et al., 2015; Nakata et al., 2016; Zhou et al., 2017; Wei et al., 2018; Zhang et al., 2018, 2019; Xiong et al., 2019). For example, the electrochemical performances of crystalline host materials relatively rely on various factors, such as the available energetically equivalent sites for guestion occupation/transport, crystal orientation, structural stability, phase transition, the spatial dimension of ion migration, defects in crystal, and the stoichiometric limitation of ion insertion (Liu et al., 2015; Xiang et al., 2015; Deng et al., 2017; Wang et al., 2018).Compared to those crystalline electrodes, the amorphous counterparts could deliver much improved specific capacities and long-term cyclability over a wide potential window (Mathew et al., 2014; Wei et al., 2018; Zhang et al., 2019). This is because the amorphous phases exhibit several advantages, such as improved ionic intercalation/deintercalation kinetics due to the existence of percolation pathways, a larger free volume, and higher specific surface area to accommodate lattice distortions.

Various routes can be applied to amorphize or vitrify the corresponding crystal materials. Besides the conventional meltquenching method (Nakata et al., 2016; Zhang et al., 2018; Fan et al., 2019), there are many other techniques such as ball milling (Kapaev et al., 2017; Xiong et al., 2019), electrochemically induced amorphization (Kim et al., 2015; Rahman et al., 2017; Liu et al., 2018), sol-gel (Fang et al., 2014; Mathew et al., 2014), and magnetron sputtering (Baranchugov et al., 2007; Shi et al., 2009). Here we focus on only three techniques for amorphization: melt quenching, mechanochemical ball milling, and electrochemically induced amorphization. We give a short review about the recent progress in developing high-performance electrode materials for AIBs by means of amorphization engineering. We also describe the microscopic mechanisms of the amorphizationinduced enhancement of electrochemical performances. Finally, we point out the perspectives in developing the superior electrode materials via amorphization.

\section{AMORPHOUS PHASE IN NaFePO 4 -BASED CATHODE}

Owing to the excellent structural stability of polyanions, many types of phosphates have been considered to be promising cathode materials for AIBs (Padhi et al., 1997; Masquelier and Croguennec, 2013; An et al., 2015; Xiong et al., 2017; Yin et al., 2017). For example, olivine $\mathrm{LiFePO}_{4}$, a typical representative of phosphate cathode materials, is one of the best cathode materials for LIBs (Padhi et al., 1997; Zhang et al., 2014; Guo et al., 2015). However, maricite $\mathrm{NaFePO}_{4}$, thermodynamically stable sodium analog of $\mathrm{LiFePO}_{4}$, delivers low sodium storage activity due to the absence of sodium-ion diffusion channels (Zaghib et al., 2011; Prosini et al., 2014). Some traditional strategies, e.g., increasing work temperature (Zaghib et al., 2011), carbon coating (Sun A. et al., 2012), and reducing grain size (Prosini et al., 2014), have been employed to modify the electrochemical performances of maricite $\mathrm{NaFePO}_{4}$, but the enhancement is still not satisfying.
Thus, it is necessary to find an alternative better strategy for enhancing the sodium storage performance of $\mathrm{NaFePO}_{4}$.

Recently, through amorphization, an important breakthrough was achieved in enhancing the Na-storage performance of maricite-type $\mathrm{NaFePO}_{4}$ (Kim et al., 2015; Rahman et al., 2017; Liu et al., 2018; Xiong et al., 2019). Unexpectedly, after desodiation at high potential $\left(4.5 \mathrm{~V}\right.$ vs. $\left.\mathrm{Na}^{+} / \mathrm{Na}\right)$ for $5 \mathrm{~h}$, the maricite $\mathrm{NaFePO}_{4}$ exhibited a high reversible sodium storage capacity of $142 \mathrm{~mA} \mathrm{~h} \mathrm{~g}^{-1}$ at $\mathrm{C} / 20$ without obvious decay after 200 cycles (Kim et al., 2015). Based on the Xray diffraction, extended $\mathrm{X}$-ray absorption fine structure, and high-resolution electron transmission microscopy technologies, the transformation of maricite $\mathrm{NaFePO}_{4}$ into amorphous $\mathrm{FePO}_{4}$ after the prime high-potential desodiation process was observed, which could be responsible for the greatly enhanced electrochemical performances. Compared to the directly synthesized amorphous $\mathrm{FePO}_{4}$, the amorphous phase transformed from the maricite $\mathrm{NaFePO}_{4}$ shows high structural stability that benefits the ion storage (Liu et al., 2012; Fang et al., 2014). Understanding of the amorphization process is crucial for elucidating the atomistic-scale structural origin of the above-mentioned phenomenon.

Following this observation, other optimization strategies were also applied to further improve the electrochemical performances of electrochemically induced amorphous $\mathrm{NaFePO}_{4}$, such as graphene modification, minimizing particle size and carbon cloth loading (Rahman et al., 2017; Liu et al., 2018; Ma et al., 2019). Combination of electrochemically induced amorphization with nanostructure design led to excellent electrochemical performances for various kinds of maricite $\mathrm{NaFePO}_{4}$-based nanocomposites. Notably, Liu et al. (2018) fabricated maricite $\mathrm{NaFePO}_{4}$ nanoparticles with minimized grain size (about $1.6 \mathrm{~nm}$ ) embedded in carbon nanofibers via electrospinning technique. Using this approach, along with the electrochemically induced amorphization, they achieved high rate performance $(61 \mathrm{~mA} \mathrm{~h}$ $\mathrm{g}^{-1}$ at $7500 \mathrm{~mA} \mathrm{~g}^{-1}$, i.e., at $50 \mathrm{C}$ ) and excellent cycling stability (capacity retention of about $89 \%$ after 6300 cycles).

In addition, the most widely used amorphization method, i.e., melt-quenching method, also has been attempted to attain amorphous $\mathrm{NaFePO}_{4}$ (Nakata et al., 2016). Unfortunately, the $\mathrm{NaFePO}_{4}\left(50 \mathrm{FeO} \cdot 50 \mathrm{NaPO}_{3}\right)$ glass has not been successfully prepared due to the strong crystallization tendency of its melt. However, the $40 \mathrm{FeO} \cdot 60 \mathrm{NaPO}_{3}$ glass was obtained, which exhibits a capacity of $115 \mathrm{~mA} \mathrm{~h} \mathrm{~g}^{-1}$ at $0.1 \mathrm{C}$ when evaluated as a cathode material for SIBs, demonstrating the sodium storage activity of $\mathrm{FeO}-\mathrm{NaPO}_{3}$ glasses. Moreover, some glass-ceramic electrode materials were obtained via melt-quenching method, which also display excellent electrochemical performances (Honma et al., 2012, 2013, 2014; Tanabe et al., 2018). In these electrodes, the crystal phases play a dominant role in enhancing the electrochemical activity. However, there is a lack of in-depth investigations with respect to the role of glass phases.

Employing another amorphization approach, i.e., mechanochemical ball milling, we attempt to obtain amorphous $\mathrm{NaFePO}_{4}$ (Xiong et al., 2019). Systematic calorimetric characterizations indicate that the glass transition was not observed prior to the sharp crystallization peak, verifying 

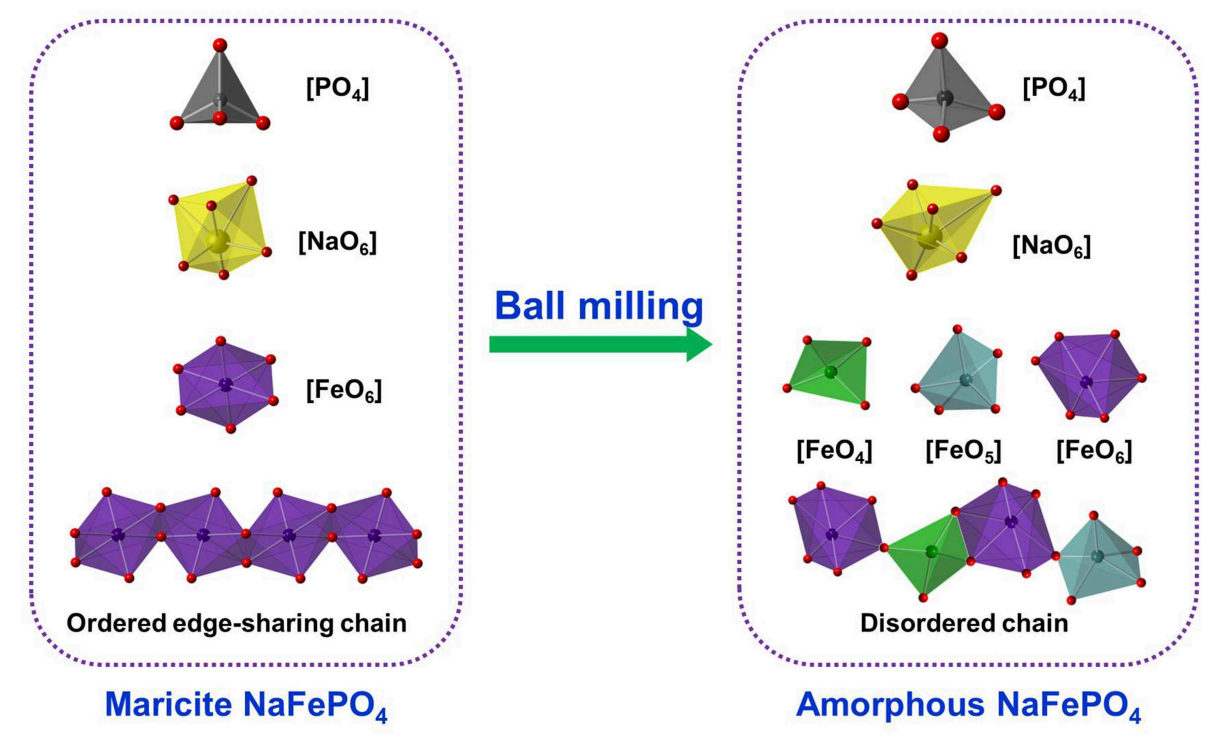

FIGURE 1 | Structural evolution of network forming motifs and intermediate range cationic order from maricite-type to amorphous $\mathrm{NaFePO}_{4}$ phase.

that $\mathrm{NaFePO}_{4}$ is a poor glass former, coinciding with the failure in preparing $\mathrm{NaFePO}_{4}$ glass though melt-quenching method (Nakata et al., 2016). Through adjusting the ball-milling parameters, a series of $\mathrm{NaFePO}_{4}$ composites with different fractions of amorphous phase (i.e., with different ratios of crystal to amorphous phases) were fabricated. The detailed characterizations of electrochemical performances confirmed the positive correlation between the amorphous degree and sodium storage capacity. However, the nanocrystals embedded in amorphous $\mathrm{NaFePO}_{4}$ matrix also play a key role in boosting the structural stability, leading to an enhancement of cycling stability. Also, the optimized $\mathrm{NaFePO}_{4}$ composite delivers an initial capacity of $115 \mathrm{~mA} \mathrm{~h} \mathrm{~g}^{-1}$ at $1 \mathrm{C}\left(155 \mathrm{~mA} \mathrm{~g}^{-1}\right)$ with capacity retention of $91.3 \%$ after 800 cycles. Furthermore, systematic structural characterizations, such as the X-ray absorption near edge and Raman spectroscopy, were performed to reveal the atomic-scale structural evolution of $\mathrm{NaFePO}_{4}$ from crystalline to amorphous phase (Xiong et al., 2019). For example, according to the $\mathrm{O} \mathrm{K}$-edge $\mathrm{X}$-ray absorption near edge spectra, the decrease of the nearest coordination number of oxygen was verified after amorphization. As shown in Figure 1, upon amorphization, the relatively symmetrical $\mathrm{FeO}_{6}$ octahedra become distorted $\mathrm{Fe}-\mathrm{O}$ polyhedra, such as mainly octahedra, pentahedra, and tetrahedra, while the isolated $\mathrm{P}-\mathrm{O}$ tetrahedral units remain unaffected (Xiong et al., 2019). Possibly due to the relatively weaker bonding strength of $\mathrm{Fe}-\mathrm{O}$ bonds compared to the $\mathrm{P}-\mathrm{O}$ ones, the nearest coordination environment of $\mathrm{Fe}$ could be easier to be altered than that of phosphorus. The above-mentioned evolution in the local surroundings of iron and oxygen could result in the statistical distortion and asymmetry of sodium sites, and thus enhances the potential energy and instability of sodium sites and decreases the activation barriers of sodium-ion diffusion. Therefore, these work further revealed the functionalities of both amorphous and crystal phases together with their atomistic-scale mechanism.

\section{GLASS PHASE IN $\mathrm{V}_{2} \mathrm{O}_{5}-\mathrm{TeO}_{2}$ GLASS-BASED ANODE}

Glass-based anodes for LIBs, especially Sn-based glassy materials, have attracted much attention (Courtney, 1997; Idota et al., 1997; Machill et al., 1999; Morimoto et al., 1999, 2001; Goward et al., 2000; Lee et al., 2000; Hayashi et al., 2004; Kebede et al., 2018). For instance, the $\mathrm{Sn}_{1.0} \mathrm{~B}_{0.56} \mathrm{P}_{0.40} \mathrm{Al}_{0.42} \mathrm{O}_{3.6}$ glass-based anode displayed a capacity retention of $90 \%$ after 100 cycles, which is better than that of SnO powder (Idota et al., 1997). However, the other Sn-based glass anodes exhibited poor cycling stability (Courtney, 1997; Machill et al., 1999; Lee et al., 2000; Morimoto et al., 2001). The metallic Sn clusters could precipitate from the Sn-based glass and aggregate during the charging/discharging process, leading to fast capacity fading (Courtney, 1997; Machill et al., 1999; Lee et al., 2000). To alleviate the capacity fading, much work was done, e.g., adjusting the charging/discharging voltage range and modifying the composition, while the achieved cycling stability is still unsatisfied (below 50 cycles) (Courtney, 1997; Lee et al., 2000; Morimoto et al., 2001; Hayashi et al., 2004). Therefore, it is a big challenge to further improve the cyclability of glass-based anodes. Encouragingly, some important improvements were obtained in some recent studies (Zhang et al., 2018, 2019; Fan et al., 2019).

Recently, utilizing its attractive lithium storage ability and high electronic conductivity (Dhawan et al., 1982; Levy et al., 1989; Levy and Souquet, 1989; Kjeldsen et al., 2013; Fan et al., 2019), Zhang et al. investigated the $\mathrm{V}_{2} \mathrm{O}_{5}-\mathrm{TeO}_{2}$ glass system as anode materials and achieved a breakthrough in 

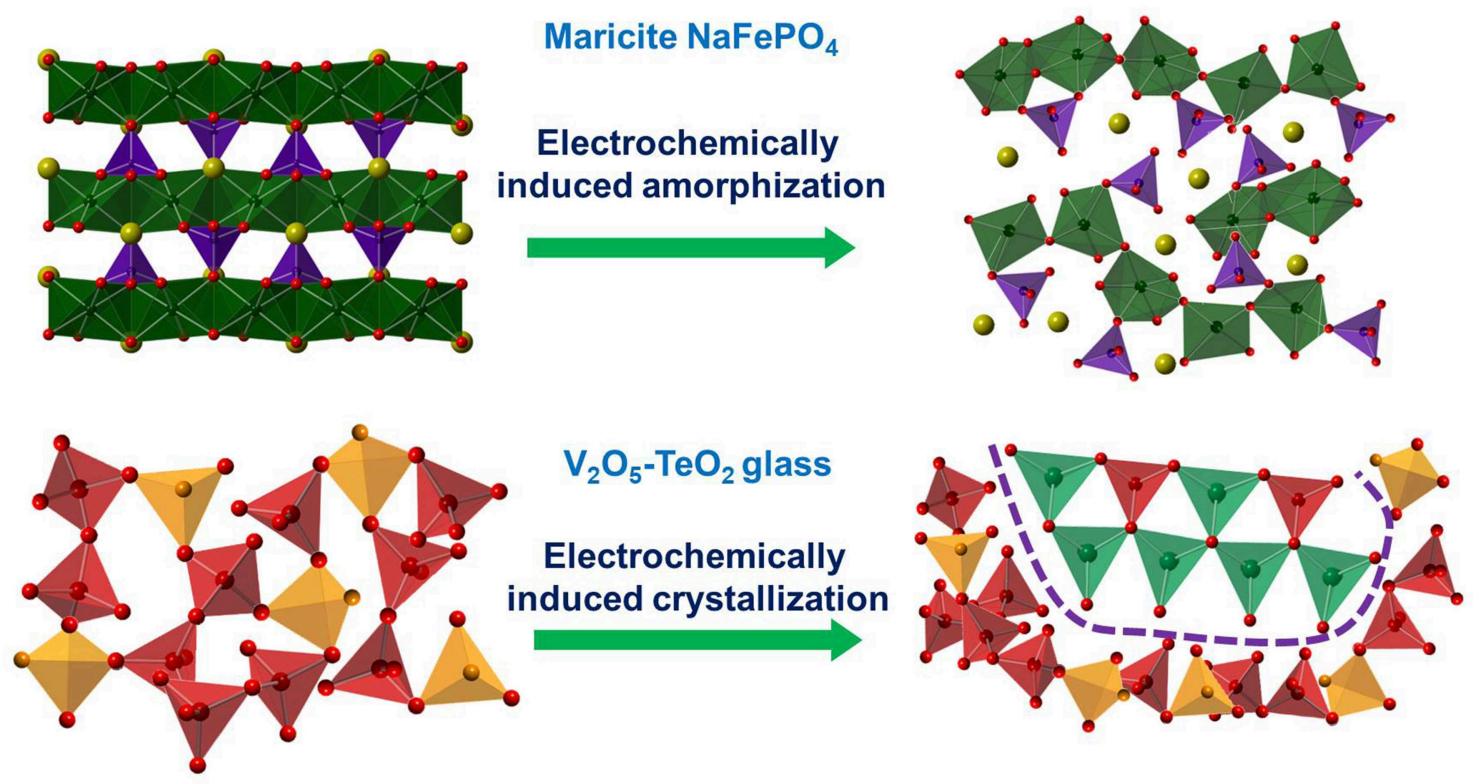

$\mathrm{Na}$
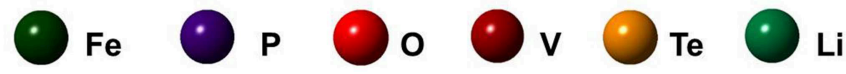

FIGURE 2 | Schematic diagram of structural evolution of electrochemically induced amorphization (maricite-type phase $\mathrm{NaFePO}_{4}$ as an example) or crystallization $\left(\mathrm{V}_{2} \mathrm{O}_{5}-\mathrm{TeO}_{2}\right.$ glass as an example).

enhancing the cycling stability (Zhang et al., 2018, 2019). In contrast to the electrochemically induced amorphization in maricite $\mathrm{NaFePO}_{4}$, the electrochemically induced nanocrystals was observed in the $\mathrm{V}_{2} \mathrm{O}_{5}-\mathrm{TeO}_{2}$ glass-based anode (Figure 2) (Zhang et al., 2018). Even during the first discharge process, the nanocrystals precipitate in the glass matrix and gradually grow upon the subsequent cycles. The nanocrsytals are uniformly distributed in glass matrix and play an important role in stabilizing the structure. Hence, during the long-term discharging/charging cycling process, this stable structure can maintain, resulting in an enhanced cycling stability. In addition, the electrochemical impedance spectroscopy plots imply that the electronic conduction and lithium-ion diffusion in $\mathrm{V}_{2} \mathrm{O}_{5}$ $\mathrm{TeO}_{2}$ glass-based anode could be promoted after 1,000 cycles compared to the pristine one. Benefiting from the synergistic effects of nanocrystals and glass matrix, the $\mathrm{V}_{2} \mathrm{O}_{5}-\mathrm{TeO}_{2}$ glassbased anode displays significantly improved cycling stability and excellent rate performance. The reversible capacity of the optimized glass-based anode with the composition $60 \mathrm{~V}_{2} \mathrm{O}_{5}$ $40 \mathrm{TeO}_{2}$ still remained about $132 \mathrm{~mA} \mathrm{~h} \mathrm{~g}^{-1}$ after 1,000 cycles at $1,000 \mathrm{~mA} \mathrm{~g}^{-1}$.

The above-mentioned work demonstrates the crucial effect of nanocrystals embedded in glass on electrochemical performances of $\mathrm{V}_{2} \mathrm{O}_{5}-\mathrm{TeO}_{2}$ glassy anode. However, both the nanocrystal formation and the detailed mechanism of the enhancement of electrochemical performances still need to be understood. Therefore, to do so, further efforts were made in another study (Zhang et al., 2019). The enthalpy relaxation behaviors of fastquenched $60 \mathrm{~V}_{2} \mathrm{O}_{5}-40 \mathrm{TeO}_{2}$ glass confirmed its high structural and energetic heterogeneity. The high-energy domains are vulnerable to the insertion/extraction of lithium ions. Thus, these domains are easily converted to the ordered ones, driven by the decrease of the Gibbs free energy. In addition, more free space could occur as a result of the volume shrinkage caused by the nanocrystal formation, especially in the interphase between nanocrystals and glass matrix, thereby enhancing both the storage and the diffusion of lithium ions. In addition, during the long-term cycling process, the nanocrystals transform from the $\mathrm{LiVO}_{3}$ phase to the electrochemically active $\gamma-\mathrm{Li}_{3} \mathrm{VO}_{4}$ phase, and after 5000 cycles, the latter phase becomes the dominating one, which has higher ionic conductivity. Consequently, the $60 \mathrm{~V}_{2} \mathrm{O}_{5}$ $40 \mathrm{TeO}_{2}$ glass-based anode exhibits excellent rate performance. On the other hand, the enhanced cycling stability of $60 \mathrm{~V}_{2} \mathrm{O}_{5^{-}}$ $40 \mathrm{TeO}_{2}$ glass-based anode is associated with the strengthened structure. The glass matrix can buffer the volume variation during the repeated insertion/extraction of lithium ions due to the open network structure. Moreover, the nanocrystals and the free space between nanocrystals and glass matrix could play a critical role in hindering the propagation of the micro-cracks.

Furthermore, the type of the discharging/charging-induced nanocrystals depends on the glass composition. For $50 \mathrm{TeO}_{2}$ $50 \mathrm{~V}_{2} \mathrm{O}_{5}$ glass doped with $5 \mathrm{~mol} \% \mathrm{Al}_{2} \mathrm{O}_{3}$, the metallic Te nanocrystals could be generated from the glass matrix upon the discharging/charging cycles, and hence, the electrochemical performances of this $\mathrm{Al}_{2} \mathrm{O}_{3}$-doped glass are highly different from those of the above-mentioned $\mathrm{V}_{2} \mathrm{O}_{5}-\mathrm{TeO}_{2}$ glass (Fan et al., 2019). Interestingly, this nanocrystal/glass composite also possesses excellent cycling stability. After 1,000 cycles at $1,000 \mathrm{~mA} \mathrm{~g}^{-1}$, the capacity of $202 \mathrm{~mA} \mathrm{~h} \mathrm{~g}^{-1}$ was also remained. 


\section{OUTLOOK AND PERSPECTIVES}

We have reviewed recent advances in developing electrode materials for AIBs by amorphization engineering. The positive effects of amorphization engineering on $\mathrm{Li} / \mathrm{Na}$ ion storage and transfer kinetics of electrode materials were confirmed by several representative cases. Electrochemically induced amorphization and nanocrystal formation were observed in $\mathrm{NaFePO}_{4}$-based crystal cathode and $\mathrm{V}_{2} \mathrm{O}_{5}-\mathrm{TeO}_{2}$ glass-based anode upon charging/discharging cycling, respectively. Interestingly, the nanocrystals in disordered matrix played an important role in enhancing the electrochemical performances of AIBs. In other words, tuning of order/disorder in electrodes can lead to considerable improvement of the AIB performances.

Despite the above-mentioned advances in developing electrode materials, several challenging problems still remain to be tackled. For $\mathrm{NaFePO}_{4}$ cathodes, there is no direct evidence for the Na-storage mechanism of the nanocrystalline/amorphous composite. The synthesis of fully amorphous $\mathrm{NaFePO}_{4}$ will be a crucial step for further understanding the effect of nanocrystals in amorphous matrix on the electrochemical performances of the cathodes for SIBs. For $\mathrm{V}_{2} \mathrm{O}_{5}-\mathrm{TeO}_{2}$ glass-based anodes, the

\section{REFERENCES}

An, Q., Lv, F., Liu, Q., Han, C., Zhao, K., Sheng, J., et al. (2014). Amorphous vanadium oxide matrixes supporting hierarchical porous $\mathrm{Fe}_{3} \mathrm{O}_{4}$ /graphene nanowires as a high-rate lithium storage anode. Nano Lett. 14, 6250-6256. doi: $10.1021 / \mathrm{nl} 5025694$

An, Q., Xiong, F., Wei, Q., Sheng, J., He, L., Ma, D., et al. (2015). Nanoflake-assembled hierarchical $\mathrm{Na}_{3} \mathrm{~V}_{2}\left(\mathrm{PO}_{4}\right)_{3} / \mathrm{C}$ microflowers: superior $\mathrm{Li}$ storage performance and insertion/extraction mechanism. Adv. Energy Mater. 5:1401963. doi: 10.1002/aenm.201401963

Baranchugov, V., Markevich, E., Pollak, E., Salitra, G., and Aurbach, D. (2007). Amorphous silicon thin films as a high capacity anodes for Liion batteries in ionic liquid electrolytes. Electrochem. Commun. 9, 796-800. doi: 10.1016/j.elecom.2006.11.014

Courtney, I. A. (1997). Key factors controlling the reversibility of the reaction of lithium with $\mathrm{SnO}_{2}$ and $\mathrm{Sn}_{2} \mathrm{BPO}_{6}$ glass. J. Electrochem. Soc. 144:2943. doi: $10.1149 / 1.1837941$

Deng, Y., Yang, C., Zou, K., Qin, X., Zhao, Z., and Chen, G. (2017). Recent advances of $\mathrm{Mn}$-rich $\mathrm{LiFe}_{1-\mathrm{y}} \mathrm{Mn}_{\mathrm{y}} \mathrm{PO}_{4}(0.5 \leq \mathrm{y}<1.0)$ cathode materials for high energy density lithium ion batteries. Adv. Energy Mater. 7:1601958. doi: 10.1002/aenm.201601958

Dhawan, V. K., Mansingh, A., and Sayer, M. (1982). DC conductivity of $\mathrm{V}_{2} \mathrm{O}_{5}-\mathrm{TeO}_{2}$ glasses. J. Non-Cryst. Solids 51, 87-103. doi: 10.1016/0022-3093(82)90190-9

Fan, J., Zhang, Y., Li, G., and Yue, Y. (2019). Tellurium nanoparticles enhanced electrochemical performances of $\mathrm{TeO}_{2}-\mathrm{V}_{2} \mathrm{O}_{5}-\mathrm{Al}_{2} \mathrm{O}_{3}$ glass anode for Lithium-ion batteries. J. Non-Cryst. Solids 521:119491. doi: 10.1016/j.jnoncrysol.2019.119491

Fang, Y., Xiao, L., Qian, J., Ai, X., Yang, H., and Cao, Y. (2014). Mesoporous amorphous $\mathrm{FePO}_{4}$ nanospheres as high-performance cathode material for sodium-ion batteries. Nano Lett. 14, 3539-3543. doi: 10.1021/nl501152f

Goodenough, J. B., and Park, K. S. (2013). The Li-ion rechargeable battery: a perspective. J. Am. Chem. Soc. 135, 1167-1176. doi: 10.1021/ ja3091438

Goward, G. R., Nazar, L. F., and Power, W. P. (2000). Electrochemical and multinuclear solid-state NMR studies of tin composite oxide glasses as anodes for Li ion batteries. J. Mater. Chem. 10, 1241-1249. doi: 10.1039/ b001352h formation mechanism of $\mathrm{LiVO}_{3}$ and $\gamma-\mathrm{Li}_{3} \mathrm{VO}_{4}$ is still not fully clear. Moreover, the relation between the glass composition and the nanocrystal formation induced by the electrochemical cycles needs to be clarified. We still need to answer the question why the electrochemically induced amorphization or crystallization occurs in different electrode materials. Finally, the electrochemical performances of the electrode materials obtained by amorphization engineering should also be evaluated in the energy storage units, particularly regarding the initial Coulombic efficiencies, the specific capacity, and the energy density of AIBs.

\section{AUTHOR CONTRIBUTIONS}

FX was responsible for writing and formatting the article. HT and YY supervised and revised the manuscript.

\section{FUNDING}

This work was supported by the National Natural Science Foundation of China (Nos. 51772223 and 51372180).
Guo, L., Zhang, Y., Wang, J., Ma, L., Ma, S., Zhang, Y., et al. (2015). Unlocking the energy capabilities of micron-sized $\mathrm{LiFePO}_{4}$. Nat. Commun. 6:7898. doi: $10.1038 /$ ncomms 8898

Hayashi, A., Konishi, T., Tadanaga, K., Minami, T., and Tatsumisago, M. (2004). Preparation and characterization of $\mathrm{SnO}-\mathrm{P}_{2} \mathrm{O}_{5}$ glasses as anode materials for lithium secondary batteries. J. Non-Cryst. Solids 345-346, 478-483. doi: 10.1016/j.jnoncrysol.2004.08.069

Honma, T., Ito, N., Togashi, T., Sato, A., and Komatsu, T. (2013). Triclinic $\mathrm{Na}_{2--x} \mathrm{Fe}_{1+\mathrm{x} / 2} \mathrm{P}_{2} \mathrm{O}_{7} / \mathrm{C}$ glass-ceramics with high current density performance for sodium ion battery. J. Power Sources 227, 31-34. doi: 10.1016/j.jpowsour.2012.11.030

Honma, T., Sato, A., Ito, N., Togashi, T., Shinozaki, K., and Komatsu, T. (2014). Crystallization behavior of sodium iron phosphate glass $\mathrm{Na}_{2--x} \mathrm{Fe}_{1+0.5 \mathrm{x}} \mathrm{P}_{2} \mathrm{O}_{7}$ for sodium ion batteries. J. Non-Cryst. Solids 404, 26-31. doi: 10.1016/j.jnoncrysol.2014.07.028

Honma, T., Togashi, T., Ito, N., and Komatsu, T. (2012). Fabrication of $\mathrm{Na}_{2} \mathrm{FeP}_{2} \mathrm{O}_{7}$ glass-ceramics for sodium ion battery. J. Ceram. Soc. Jpn. 120, 344-346. doi: $10.2109 /$ jcersj2.120.344

Idota, Y., Kubota, T., Matsufuji, A., Maekawa, Y., and Miyasaka, T. (1997). Tinbased amorphous oxide: a high-capacity lithium-ion-storage material. Science 276, 1395-1397. doi: 10.1126/science.276.5317.1395

Kang, B., and Ceder, G. (2009). Battery materials for ultrafast charging and discharging. Nature 458, 190-193. doi: 10.1038/nature07853

Kapaev, R., Chekannikov, A., Novikova, S., Yaroslavtsev, S., Kulova, T., Rusakov, V., et al. (2017). Mechanochemical treatment of maricite-type $\mathrm{NaFePO}_{4}$ for achieving high electrochemical performance. J. Solid State Electrochem. 21, 2373-2380. doi: 10.1007/s10008-017-3592-5

Kebede, M. A., Palaniyandy, N., Ramadan, R. M., and Sheha, E. (2018). The electrical and electrochemical properties of graphene nanoplatelets modified $75 \mathrm{~V}_{2} \mathrm{O}_{5}-25 \mathrm{P}_{2} \mathrm{O}_{5}$ glass as a promising anode material for lithium ion battery. $J$. Alloys Compd. 735, 445-453. doi: 10.1016/j.jallcom.2017.11.136

Kim, J., Seo, D.-H., Kim, H., Park, I., Yoo, J.-K., Jung, S.-K., et al. (2015). Unexpected discovery of low-cost maricite $\mathrm{NaFePO}_{4}$ as a highperformance electrode for Na-ion batteries. Energy Environ. Sci. 8, 540-545. doi: 10.1039/C4EE03215B

Kjeldsen, J., Yue, Y., Bragatto, C. B., and Rodrigues, A. C. M. (2013). Electronic conductivity of vanadium-tellurite glass-ceramics. J. Non-Cryst. Solids 378, 196-200. doi: 10.1016/j.jnoncrysol.2013.07.011 
Larcher, D., and Tarascon, J. M. (2015). Towards greener and more sustainable batteries for electrical energy storage. Nat. Chem. 7, 19-29. doi: $10.1038 /$ nchem. 2085

Lee, J., Kitchaev, D. A., Kwon, D. H., Lee, C. W., Papp, J. K., Liu, Y. S., et al. (2018). Reversible $\mathrm{Mn}^{2+} / \mathrm{Mn}^{4+}$ double redox in lithium-excess cathode materials. Nature 556, 185-190. doi: 10.1038/s41586-018-0015-4

Lee, J., Urban, A., Li, X., Su, D., Hautier, G., and Ceder, G. (2014). Unlocking the potential of cation-disordered oxides for rechargeable lithium batteries. Science 343, 519-522. doi: 10.1126/science. 1246432

Lee, J. Y., Xiao, Y. W., and Liu, Z. L. (2000). Amorphous $\mathrm{Sn}_{2} \mathrm{P}_{2} \mathrm{O}_{7}, \mathrm{Sn}_{2} \mathrm{~B}_{2} \mathrm{O}_{5}$ and $\mathrm{Sn}_{2} \mathrm{BPO}_{6}$ anodes for lithium ion batteries. Solid State Ionics 133, 25-35. doi: $10.1016 /$ S0167-2738(00)00732-3

Levy, M., Duclot, M. J., and Rousseau, F. (1989). $\mathrm{V}_{2} \mathrm{O}_{5}$-based glasses as cathodes for lithium batteries. J. Power Sources 26, 381-388. doi: 10.1016/0378-7753(89)80150-8

Levy, M., and Souquet, J. L. (1989). Amorphous and vitreous materials as electrodes in electrochemical cells. Mater. Chem. Phys. 23, 171-188. doi: 10.1016/0254-0584(89)90023-0

Liu, W., Oh, P., Liu, X., Lee, M. J., Cho, W., Chae, S., et al. (2015). Nickel-rich layered lithium transition-metal oxide for high-energy lithiumion batteries. Angew. Chem. Int. Ed. 54, 4440-4457. doi: 10.1002/anie.201 409262

Liu, Y., Xu, Y., Han, X., Pellegrinelli, C., Zhu, Y., Zhu, H., et al. (2012). Porous amorphous $\mathrm{FePO}_{4}$ nanoparticles connected by single-wall carbon nanotubes for sodium ion battery cathodes. Nano Lett. 12, 5664-5668. doi: $10.1021 / \mathrm{nl} 302819 \mathrm{f}$

Liu, Y., Zhang, N., Wang, F., Liu, X., Jiao, L., and Fan, L.-Z. (2018). Approaching the downsizing limit of maricite $\mathrm{NaFePO}_{4}$ toward highperformance cathode for sodium-ion batteries. Adv. Funct. Mater. 28:1801917. doi: $10.1002 / \mathrm{adfm} .201801917$

Ma, X., Xia, J., Wu, X., Pan, Z., and Shen, P. K. (2019). Remarkable enhancement in the electrochemical activity of maricite $\mathrm{NaFePO}_{4}$ on highsurface-area carbon cloth for sodium-ion batteries. Carbon N. Y. 146, 78-87. doi: 10.1016/j.carbon.2019.02.004

Machill, S., Shodai, T., Sakurai, Y., and Yamaki, J.-i. (1999). Electrochemical and structural investigations of the reaction of lithium with tin-based composite oxide glasses. J. Solid State Electrochem. 3, 97-103. doi: 10.1007/s100080050134

Manthiram, A., Chemelewski, K., and Lee, E.-S. (2014). A perspective on the high-voltage $\mathrm{LiMn}_{1.5} \mathrm{Ni}_{0.5} \mathrm{O}_{4}$ spinel cathode for lithium-ion batteries. Energy Environ. Sci. 7:1339. doi: 10.1039/c3ee42981d

Masquelier, C., and Croguennec, L. (2013). Polyanionic (phosphates, silicates, sulfates) frameworks as electrode materials for rechargeable $\mathrm{Li}($ or $\mathrm{Na}$ ) batteries. Chem. Rev. 113, 6552-6591. doi: 10.1021/cr3001862

Mathew, V., Kim, S., Kang, J., Gim, J., Song, J., Baboo, J. P., et al. (2014). Amorphous iron phosphate: potential host for various charge carrier ions. NPG Asia Mater. 6:e138. doi: 10.1038/am.2014.98

Morimoto, H., Nakai, M., Tatsumisago, M., and Minami, T. (1999). Mechanochemical synthesis and anode properties of SnO-based amorphous materials. J. Electrochem. Soc. 146:3970. doi: 10.1149/1.1392578

Morimoto, H., Tatsumisago, M., and Minami, T. (2001). Anode properties of amorphous 50SiO-50SnO powders synthesized by mechanical milling. Electrochem. Solid State Lett. 4:A16. doi: 10.1149/1.1339239

Nakata, S., Togashi, T., Honma, T., and Komatsu, T. (2016). Cathode properties of sodium iron phosphate glass for sodium ion batteries. J. Non-Cryst. Solids 450, 109-115. doi: 10.1016/j.jnoncrysol.2016.08.005

Padhi, A. K., Nanjundaswamy, K. S., and Goodenough, J. B. (1997). Phosphoolivines as positive-electrode materials for rechargeable Lithium batteries. J. Electrochem. Soc. 144:1188. doi: 10.1149/1.1837571

Pan, H., Hu, Y.-S., and Chen, L. (2013). Room-temperature stationary sodiumion batteries for large-scale electric energy storage. Energy Environ. Sci. 6:2338. doi: $10.1039 / \mathrm{c} 3 \mathrm{ee} 40847 \mathrm{~g}$

Prosini, P. P., Cento, C., Masci, A., and Carewska, M. (2014). Sodium extraction from sodium iron phosphate with a Maricite structure. Solid State Ionics 263, 1-8. doi: 10.1016/j.ssi.2014.04.019

Qing, R.-P., Shi, J.-L., Xiao, D.-D., Zhang, X.-D., Yin, Y.-X., Zhai, Y.-B., et al. (2016). Enhancing the kinetics of Li-rich cathode materials through the pinning effects of gradient surface $\mathrm{Na}+$ doping. Adv. Energy Mater. 6:1501914. doi: 10.1002/aenm.201501914

Rahman, M. M., Sultana, I., Mateti, S., Liu, J., Sharma, N., and Chen, Y. (2017). Maricite $\mathrm{NaFePO}_{4} / \mathrm{C} /$ graphene: a novel hybrid cathode for sodium-ion batteries. J. Mater. Chem. A 5, 16616-16621. doi: 10.1039/C7 TA04946C

Shi, Q., Hu, R., Ouyang, L., Zeng, M., and Zhu, M. (2009). High-capacity $\mathrm{LiV}_{3} \mathrm{O}_{8}$ thin-film cathode with a mixed amorphous-nanocrystalline microstructure prepared by RF magnetron sputtering. Electrochem. Commun. 11, 2169-2172. doi: 10.1016/j.elecom.2009.09.022

Sun, A., Beck, F. R., Haynes, D., Poston, J. A., Narayanan, S. R., Kumta, P. N., et al. (2012). Synthesis, characterization, and electrochemical studies of chemically synthesized $\mathrm{NaFePO}_{4}$. Mater. Sci. Eng. B 177, 1729-1733. doi: 10.1016/j.mseb.2012.08.004

Sun, Y. K., Chen, Z., Noh, H. J., Lee, D. J., Jung, H. G., Ren, Y., et al. (2012). Nanostructured high-energy cathode materials for advanced lithium batteries. Nat. Mater. 11, 942-947. doi: 10.1038/nmat3435

Tanabe, M., Honma, T., and Komatsu, T. (2018). Crystallization behavior and electrochemical properties of $\mathrm{Na}_{2} \mathrm{Fe}_{\mathrm{y}} \mathrm{Mn}_{1--\mathrm{y}} \mathrm{P}_{2} \mathrm{O}_{7}$ glass. J. Non-Cryst. Solids 501, 153-158. doi: 10.1016/j.jnoncrysol.2017.12.039

Wang, P.-F., You, Y., Yin, Y.-X., and Guo, Y.-G. (2018). Layered oxide cathodes for sodium-ion batteries: Phase transition, air stability, and performance. Adv. Energy Mater. 8:17 01912. doi: 10.1002/aenm.201701912

Wei, Q., Xiong, F., Tan, S., Huang, L., Lan, E. H., Dunn, B., et al. (2017). Porous one-dimensional nanomaterials: design, fabrication and applications in electrochemical energy storage. Adv. Mater. 29:1602300. doi: 10.1002/adma.201602300

Wei, Z., Wang, D., Yang, X., Wang, C., Chen, G., and Du, F. (2018). From crystalline to amorphous: an effective avenue to engineer high-performance electrode materials for sodium-ion batteries. Adv. Mater. Interfaces 5:1800639. doi: 10.1002/admi.201800639

Xiang, X., Zhang, K., and Chen, J. (2015). Recent advances and prospects of cathode materials for sodium-ion batteries. Adv. Mater. 27, 5343-5364. doi: 10.1002/adma.201501527

Xiong, F., An, Q., Xia, L., Zhao, Y., Mai, L., Tao, H., et al. (2019). Revealing the atomistic origin of the disorder-enhanced $\mathrm{Na}$-storage performance in $\mathrm{NaFePO}_{4}$ battery cathode. Nano Energy 57, 608-615. doi: 10.1016/j.nanoen. 2018.12.087

Xiong, F., Cai, Z., Qu, L., Zhang, P., Yuan, Z., Asare, O. K., et al. (2015). Threedimensional crumpled reduced graphene oxide/ $\mathrm{MoS}_{2}$ nanoflowers: a stable anode for lithium-ion batteries. ACS Appl. Matar. Interfaces 7, 12625-12630. doi: 10.1021 /acsami.5b02978

Xiong, F., Tan, S., Wei, Q., Zhang, G., Sheng, J., An, Q., et al. (2017). Three-dimensional graphene frameworks wrapped $\mathrm{Li}_{3} \mathrm{~V}_{2}\left(\mathrm{PO}_{4}\right)_{3}$ with reversible topotactic sodium-ion storage. Nano Energy 32, 347-352. doi: 10.1016/j.nanoen.2016.12.050

Yabuuchi, N., Kubota, K., Dahbi, M., and Komaba, S. (2014). Research development on sodium-ion batteries. Chem. Rev. 114, 11636-11682. doi: $10.1021 / \mathrm{cr} 500192 \mathrm{f}$

Yin, Y., Xiong, F., Pei, C., Xu, Y., An, Q., Tan, S., et al. (2017). Robust threedimensional graphene skeleton encapsulated $\mathrm{Na}_{3} \mathrm{~V}_{2} \mathrm{O}_{2}\left(\mathrm{PO}_{4}\right)_{2} \mathrm{~F}$ nanoparticles as a high-rate and long-life cathode of sodium-ion batteries. Nano Energy 41, 452-459. doi: 10.1016/j.nanoen.2017.09.056

Zaghib, K., Trottier, J., Hovington, P., Brochu, F., Guerfi, A., Mauger, A., et al. (2011). Characterization of Na-based phosphate as electrode materials for electrochemical cells. J. Power Sources 196, 9612-9617. doi: 10.1016/j.jpowsour.2011.06.061

Zhan, C., Wu, T., Lu, J., and Amine, K. (2018). Dissolution, migration, and deposition of transition metal ions in Li-ion batteries exemplified by Mn-based cathodes-a critical review. Energy Environ. Sci. 11, 243-257. doi: 10.1039/C7EE03122J

Zhang, X., Bi, Z., He, W., Yang, G., Liu, H., and Yue, Y. (2014). Fabricating high-energy quantum dots in ultra-thin $\mathrm{LiFePO}_{4}$ nanosheets using a multifunctional high-energy biomolecule-ATP. Energy Environ. Sci. 7, 2285-2294. doi: 10.1039/C3EE44187C 
Zhang, Y., Wang, P., Li, G., Fan, J., Gao, C., Wang, Z., et al. (2019). Clarifying the charging induced nucleation in glass anode of Li-ion batteries and its enhanced performances. Nano Energy 57, 592-599. doi: 10.1016/j.nanoen. 2018.12.088

Zhang, Y., Wang, P., Zheng, T., Li, D., Li, G., and Yue, Y. (2018). Enhancing Li-ion battery anode performances via disorder/order engineering. Nano Energy 49, 596-602. doi: 10.1016/j.nanoen.2018.05.018

Zhou, M., Xu, Y., Wang, C., Li, Q., Xiang, J., Liang, L., et al. (2017). Amorphous $\mathrm{TiO}_{2}$ inverse opal anode for high-rate sodium ion batteries. Nano Energy 31, 514-524. doi: 10.1016/j.nanoen.2016.12.005
Conflict of Interest: The authors declare that the research was conducted in the absence of any commercial or financial relationships that could be construed as a potential conflict of interest.

Copyright (c) 2020 Xiong, Tao and Yue. This is an open-access article distributed under the terms of the Creative Commons Attribution License (CC BY). The use, distribution or reproduction in other forums is permitted, provided the original author(s) and the copyright owner(s) are credited and that the original publication in this journal is cited, in accordance with accepted academic practice. No use, distribution or reproduction is permitted which does not comply with these terms. 